\title{
AN EXPERIMENTAL MULTIPLE BARBED SUTURE FOR THE LONG FLEXOR TENDONS OF THE PALM AND FINGERS
}

\section{Preliminary Report}

\author{
A. R. McKenzie, Dunedin, New Zealand
}

The principle underlying the use of the internal multiple barbed suture for tendons of the palm and fingers has not been described in the surgical literature. Barbed sutures are not new, however; previous designs have had large barbs that lie on the surface of the tendon and have in general attempted to make the manoeuvres of tendon repair less tedious and less difficult. Such sutures were described by Mansberger, Jennings, Smith and Yearger (1951); Jennings, Mansberger, Smith and Yearger (1952) and by Bunnell (1954). Brooks (1963) extended the idea but has not used the suture in man. McKee (1945) used a barbed clamp to effect repair of tendons in nineteen patients.

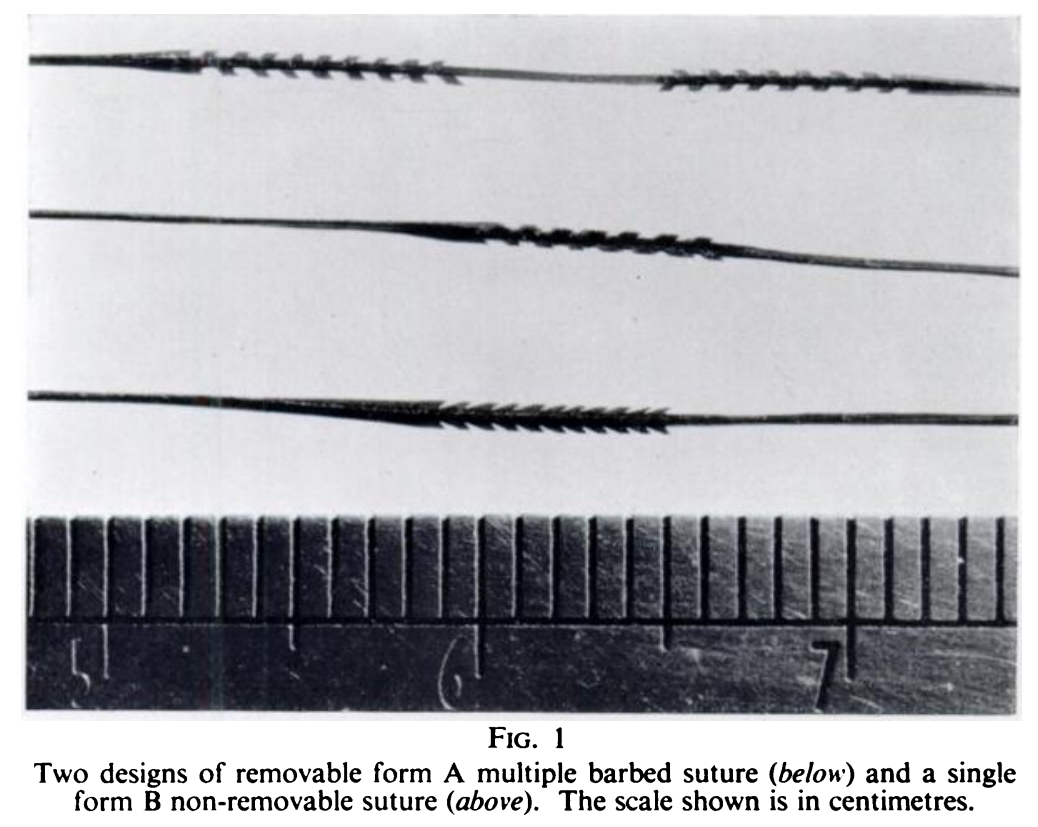

The multiple barbed suture is at present made in two forms (Fig. 1), but the design of the barbs has been varied and further variations of the general position and direction of the barbs other than that illustrated have been tried. The suture, by achieving anchorage wholly within the substance of the tendon, and thereby avoiding numerous puncture wounds and suture material on the surface of the tendon, minimises damage and foreign-body reaction just where adhesion formation is known to occur. The quantity of suture material required is small, and union is achieved easily after a little practice. There is no constriction of the tendon ends and less distortion of the stump, and this applies also to the suture-tendon junction when under tension. What little vascular tissue is present within the tendon is probably less disturbed while achieving mechanical union. Knots are avoided and the first form of the suture (the lower two designs of Figure 1) can be totally and easily removed.

The muitiple barbed suture approaches more closely the criteria for an ideal suture for tendons as set out by Mason (1940) than any so far described, and is of the core type advocated by Bunnell (1956). 


\section{STRUCTURAL DETAILS OF THE SUTURE}

The experimental multiple barbed suture is made of nylon and has numerous very fine barbs over part of its length by which it gains anchorage within the tendon. This is illustrated in principle in Figure 2, where two sutures have been used to obtain mechanical union. These sutures are removable at four weeks when union is well established. The barbs are an integral part of the nylon thread. The size of the suture for human flexor tendons, and the shape and proportions of the barbs, can be seen in Figure 1 where the scale is in centimetres. The sutures are formed from fully drawn monofilament nylon of cruciform cross-section into which the barbs are cut, making four rows of barbs for effective anchorage. There are leading and trailing portions to the thread which have no barbs but which carry the eyeless needles. The overall length of the removable type of suture (form $\mathrm{A}$ ) is approximately fifteen centimetres (six inches), and of the non-removable suture (form B) (the top suture in Figure 1) ten

TABLE I

Breaking Strength of Suture Material in Pounds Weight

\begin{tabular}{|c|c|c|c|c|c|}
\hline Material & & $\begin{array}{l}\text { Single strand } \\
\text { (pounds) }\end{array}$ & $\begin{array}{l}\text { Knotted strand } \\
\text { (pounds) }\end{array}$ & $\begin{array}{c}\text { Knotted loop } \\
(\text { pounds })\end{array}$ & $\begin{array}{c}\text { As a } \\
\text { tendon suture } \\
\text { (after Bunnell) } \\
\text { (pounds) }\end{array}$ \\
\hline $\begin{array}{l}\text { Stainless steel mono } \\
\text { G } 38 \\
\text { G } 40\end{array}$ & $\begin{array}{l}\text { ilament } \\
\cdot \quad \cdot \\
\cdot\end{array}$ & $\begin{array}{l}3 \cdot 0 \\
2 \cdot 25\end{array}$ & $\begin{array}{l}2 \cdot 75 \\
1 \cdot 25\end{array}$ & $\begin{array}{l}6 \cdot 0 \\
4 \cdot 2\end{array}$ & $\begin{array}{l}5 \cdot 0 \\
4 \cdot 5\end{array}$ \\
\hline $\begin{array}{l}\text { Stainless steel braic } \\
0000 \\
00000 .\end{array}$ & d & $\begin{array}{l}4 \cdot 2 \\
2 \cdot 2\end{array}$ & $\begin{array}{l}4 \cdot 0 \\
2 \cdot 1\end{array}$ & $\begin{array}{l}6 \cdot 5 \\
4 \cdot 5\end{array}$ & $\overline{4 \cdot 5}$ \\
\hline $\begin{array}{l}\text { Silk } \\
000 \\
0000\end{array}$ & . & $\begin{array}{l}4 \cdot 0 \\
2 \cdot 25\end{array}$ & $\begin{array}{l}3 \cdot 0 \\
2 \cdot 1\end{array}$ & $\begin{array}{l}4 \cdot 5 \\
3 \cdot 0\end{array}$ & - \\
\hline $\begin{array}{l}\text { Mersilene braided } \\
000 \\
0000\end{array}$ & . & $\begin{array}{l}4 \cdot 2 \\
3 \cdot 75\end{array}$ & $\begin{array}{l}3 \cdot 5 \\
2 \cdot 5\end{array}$ & $\begin{array}{l}7 \cdot 0 \\
6 \cdot 0\end{array}$ & $\overline{7 \cdot 0}$ \\
\hline $\begin{array}{l}\text { Nylon type } 6 \text { mono } \\
000 \\
0000 .\end{array}$ & $\begin{array}{l}\text { ilament } \\
\cdot \quad \cdot \\
\cdot \\
\cdot\end{array}$ & $\begin{array}{l}6 \cdot 0 \\
4 \cdot 0\end{array}$ & $\begin{array}{l}5 \cdot 0 \\
2 \cdot 5\end{array}$ & $\begin{array}{l}9 \cdot 5 \\
6 \cdot 0\end{array}$ & - \\
\hline $\begin{array}{l}\text { Nylon braided } \\
000 \text { ( } 3 \text { pounds }) \\
0000 \text { ( } 2 \text { pounds })\end{array}$ & . & $\begin{array}{l}4 \cdot 5 \\
2 \cdot 25\end{array}$ & $\begin{array}{l}2 \cdot 6 \\
1 \cdot 5\end{array}$ & $\begin{array}{l}6 \cdot 5 \\
4 \cdot 0\end{array}$ & - \\
\hline $\begin{array}{c}\text { Multiple barbed su } \\
0.012 \text { diameter } \\
0.010 \text { diameter }\end{array}$ & ure & $\begin{array}{l}5 \cdot 0 \\
4.0\end{array}$ & - & - & $\begin{array}{l}4 \cdot 0-6 \cdot 0 \\
4 \cdot 0-6 \cdot 0\end{array}$ \\
\hline
\end{tabular}

centimetres (four inches). The diameter of the leading and trailing threads approximates to that of 000 surgical suture material of conventional form, namely ten to twelve thousandths of an inch. The barbs are approximately ten thousandths of an inch in height, but in fact the more important dimension is the gap between the barbs which must accommodate the tendon bundles; this is also ten thousandths of an inch.

A larger suture of similar design has been found suitable for other compact tendons larger than the tendons of the fingers.

The length of the barbed section has been determined by the restricted exposure usually necessary for hand tendon repairs. Six millimetres (one-quarter of an inch) is the smallest length which gives adequate anchorage in the adult human long flexor tendon and has been determined by tests on fresh specimens. 
Table I compares the strength of the three suture materials in common use for tendon repair. The breaking strength of a single strand of conventional thread bears little relationship to the mechanical strength of a tendon repair using that thread, and conventional suturing techniques.

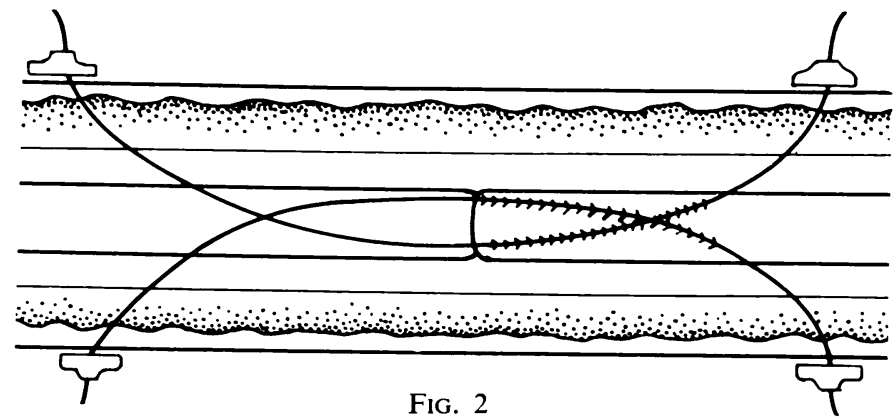

The form A of the multiple barbed suture as a removable tendon suture for the palm and finger long flexor tendons.

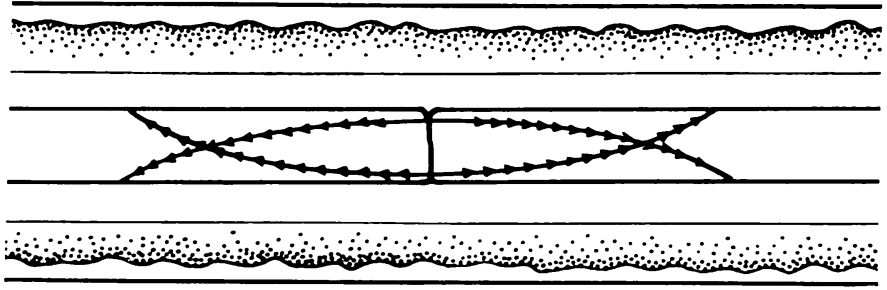

Fig. 3

The form B of the multiple barbed suture as a permanent tendon suture.

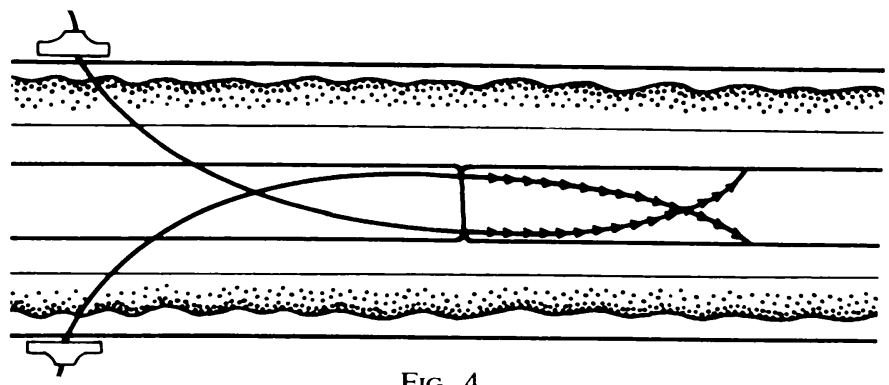

FIG. 4

Form A suture as a permanent tendon suture.

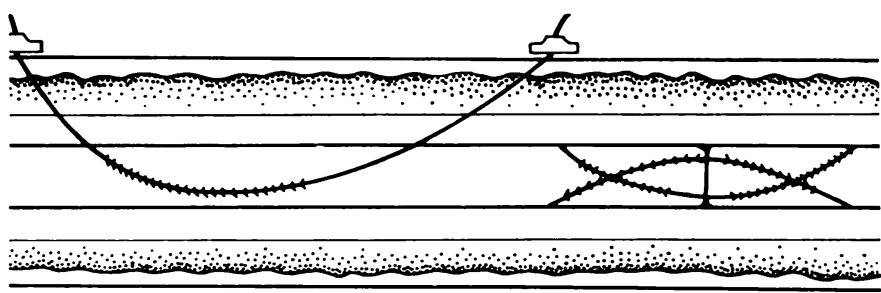

FIG. 5

Form A suture as a removable tension suture "at a distance" protecting a form $B$ repair.

The breaking strength of a single thread is an appropriate test for the multiple barbed suture because of the different mode of anchorage. Despite the small dimensions of the multiple barbed suture it has adequate strength. The core thread which is equivalent to 000 
surgical size has a breaking strength of between 3.5 and 4.5 pounds. Two such threads of the multiple barbed suture hold the tendon stumps together (Fig. 2).

The non-removable suture (form B) has two opposing barbed sections of the same dimensions as those of the removable suture (form A): these are separated by a central portion of thread without barbs of six millimetres or more (three-sixteenths or more of an inch) in length depending on the size of the tendon to be repaired and the form of the repair (Figs. 3, 5, 7 and 10$)$.

The multiple barbed suture has been designed so that the whole of the barbed section would be buried within the tendon stump but in practice this need not necessarily be so. In these circumstances anchorage strength will be less and trauma to the exterior will be slightly greater but there will be no difficulty on removal. The removable suture when inserted as recommended will only have the unbarbed portions of the thread lying in the tendon sheath

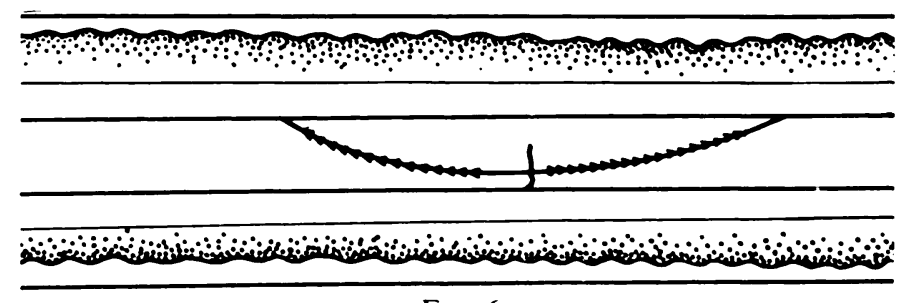

Fig. 6

A single form B suture used for a permanent suture for a partially divided tendon.

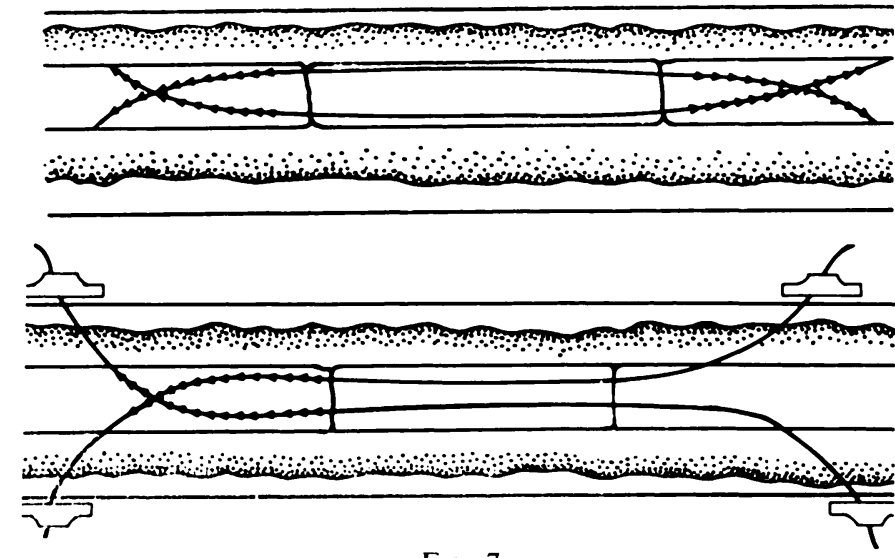

FIG. 7

A multiple barbed suture used as a permanent (above) or removable (below') suture for a "bridge" graft of a tendon.

space (Fig. 2) and they cause no more damage than conventional threads. Damage to the peritenon is limited to four puncture holes with this method of repair. The amount of distortion to the tendon ends is comparable only to that described by Verdan (1960). The skin surface anchorage for the removable sutures (Fig. 2) is secured with crimped buttons of soft metal.

One suture alone is capable of holding the two tendon stumps in apposition but the strength of the union is not great, unless a very long barbed section is incorporated in the suture within the tendon. The sutures illustrated here are most reliable when two are used for each repair and when crossed within the tendon as in Figure 2. The two sutures give better alignment of the stumps and prevent any tendency to rotation.

VOL. 49 B, No. 3, AUGUST 1967 
The form A suture can be used as a non-removable suture as in Figure 4, or as a suture at a distance (Fig. 5). The principle outlined can be modified for various situations including partial division of a tendon (Fig. 6) and bridge grafts (Fig. 7).

A suture suitable for the skin and requiring no knots is at present under investigation.

\section{TENDONS AND MATERIALS TESTED}

Many synthetic materials have been tested during the development of the present form of the multiple barbed suture. Nylon, type 610 (a hexamethylene polymer), has been used because of its greater resistance to distortion, yet retaining a very high tensile strength and a low stretch coefficient and not being too brittle. Terylene (polyethylene terephthalate), the other important surgically acceptable plastic, lacks the resistance to distortion and flows more readily under shearing and compressing forces.

Metals have proved to be too brittle. A silver wire multiple barbed suture broke with handling alone. Combinations of metal and plastic have so far been unsuccessful.

Moulded plastic materials have too low a tensile strength and begin to stretch under a very small load. The multiple barbed suture has for these reasons been manufactured from fully drawn nylon monofilaments.

The long flexor tendons are some of the most compact in the human but as with all tendons this compactness varies throughout the tendon's length. It is least at the musculotendinous junction and greatest at its narrowest part, or at that portion which passes through a pulley or over a prominence or joint. The density of the interwoven endotenon fibres which impart the property of compactness to the tendon usually diminishes again at the insertion into bone where the bundles spread out (Mollier 1937). The bundles of the human flexor digitorum profundus tendons at the level of the wrist are generally too loosely bound together to give adequate and reliable anchorage to the multiple barbed suture, but individual variations occur and occasionally one tendon at this level would be suitable. The same tendons in the palm and fingers are, however, ideally suitable for the multiple barbed suture. The flexor pollicis and sublimis tendons are also suitable.

Multiple barbed sutures therefore in the present form have limited application only to certain human and animal tendons. Whether or not a tendon is suitable can easily be determined by inspection and palpation at operation. Multiple barbed sutures are not considered necessary for the attachment of tendon to bone where "adhesion " formation is desirable.

\section{ANCHORAGE AND INSERTION}

The method of insertion of the multiple barbed suture into the tendon is of equal importance to the design of the suture to obtain maximum anchorage within the tendon substance.

In the case of the long flexor tendons of the palm and fingers, where there is a sheath and more rigid overlying tissues, surface damage is important if the gliding motion is to be restored. Further, in this situation it is also desirable, for any suturing technique, to obtain maximum anchorage in a minimum of tendon length.

The method of insertion where the tendon end needs to be trimmed to remove contaminated or ragged portions is illustrated in Figure 8. The method of inserting multiple barbed suture where the tendon end does not require to be trimmed is illustrated in Figures 9 and 10 .

\section{THE USE OF THE MULTIPLE BARBED SUTURE IN THE CADAVER}

The techniques described above have been tested in cadavers and a neat repair with adequate strength can be achieved with severed long flexor tendons (Fig. 11). The method 
does not make tendon repair any easier, nor does the suture alter indications for surgery or the management afterwards. The suture does not allow early mobilisation of the repaired tendon, and the greatest difficulty is avoiding excessive handling. The multiple barbed suture enables repair to be made with a minimum of suture material and a minimum of damage to

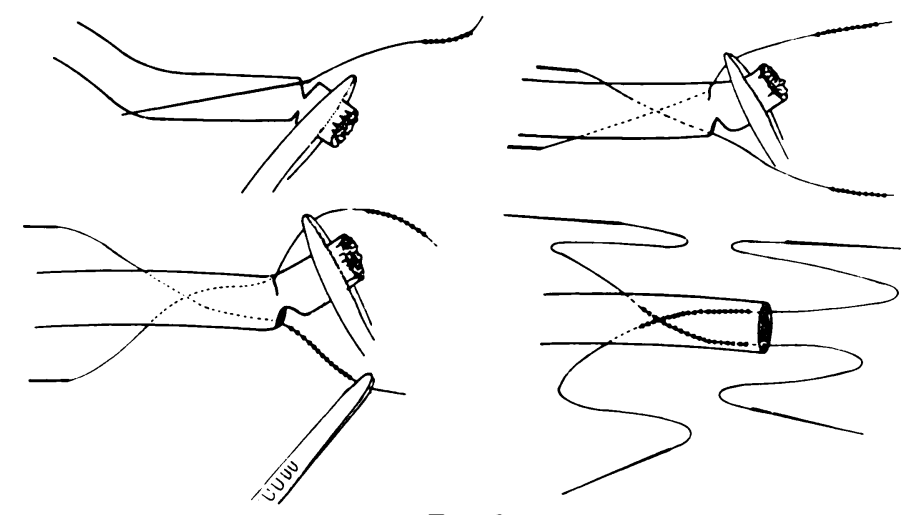

Fig. 8

A method of inserting two form A sutures to achieve maximum anchorage and minimum exterior damage from handling and puncture wounds when the tendon stump needs to be trimmed.

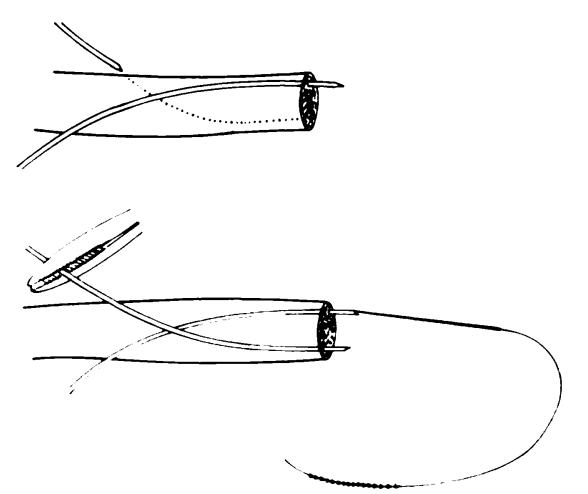

FIG. 9

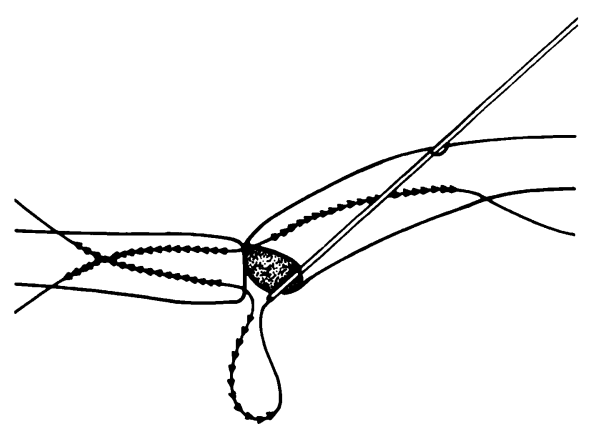

Fig. 10

Figure 9-A method of inserting two form A sutures when the stump does not require to be trimmed.

Figure 10-The final step in apposing the stumps of a tendon when using two form B sutures.

the surface of the tendon. Figure 11 illustrates a repair of the flexor profundus digitorum tendon of the index finger. For the purposes of comparison, repair of a flexor digitorum profundus tendon using stainless steel wire and the Bunnell technique is illustrated in Figure 12. The strength of the two types of repair are comparable, namely 2-2.5 kilograms (4-6 pounds) (Table I).

THE USE OF THE MULTIPLE BARBED SUTURE IN THE EXPERIMENTAL ANIMAL

A series of repairs of divided flexor digitorum profundus tendons in living dogs indicated that the experimental suture is mechanically equal to a repair, under control conditions, of the same type of tendon using gauge 40 stainless steel wire, as advocated by Pulvertaft (1965) and using the technique described by Bunnell (1956). Both suturing techniques, for the purpose of reducing trauma of handling to a minimum in experimental conditions, employed the 
modification described by Potenza (1962). This excellent study of the repair process for tendon was used as the prototype for the above investigation, with the exception that the dogs of this series had the paw protected by plaster for five weeks only. The animal's paws were then mobilised until full recovery. Under such rigorous conditions equal numbers of the

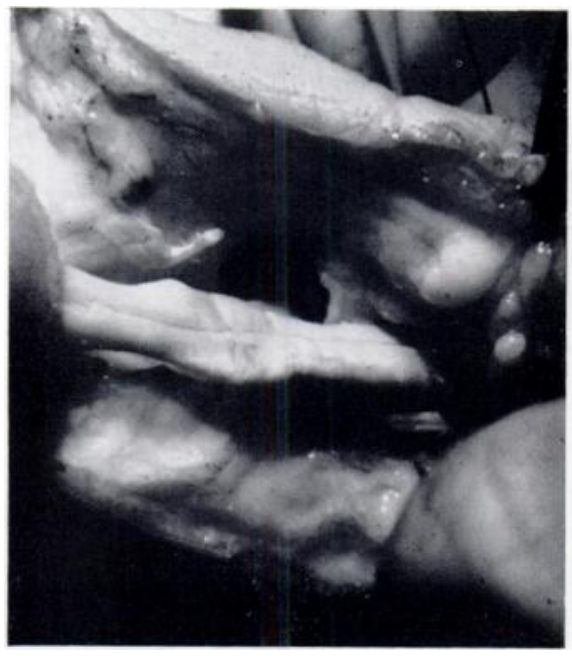

Fig. 11

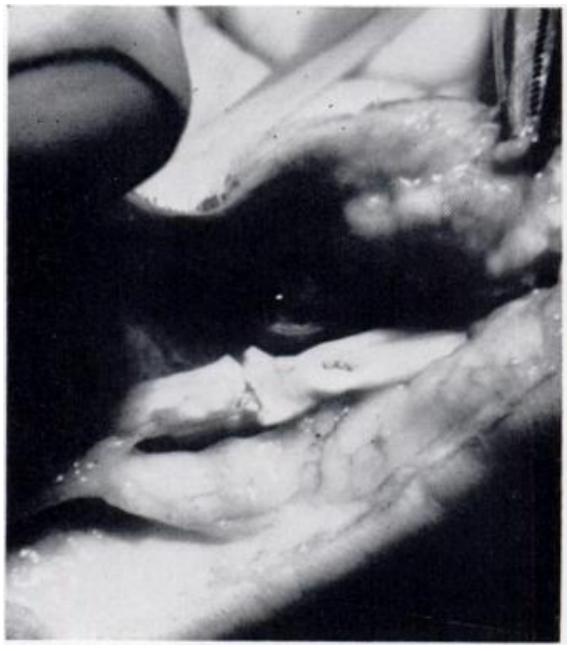

Fig. 12

Figure 11-The flexor digitorum profundus tendon of the index finger repaired with two form $B$ sutures in a cadaver. Figure 12-The flexor digitorum profundus tendon of the index finger of a cadaver repaired with gauge 40 stainless steel wire using the buried core stitch.

experimental and the control repairs were a mechanical success. The numbers available for this initial study are not sufficient for statistical analysis. A satisfactory method for the quantitative assessment of the adhesions formed with the two techniques is the subject of a further study.

\section{SUMMARY}

1. Multiple barbed sutures made from nylon are described and the theoretical advantages with the use of the nylon are outlined.

2. Methods of joining tendon stumps using the multiple barbed sutures are illustrated and in vitro tests show that the anchorage of this suture in cadaveric and canine flexor tendons is of the same order.

3. Preliminary in vivo tests where the flexor digitorum profundus tendon of dogs have been repaired with multiple barbed sutures show that it maintains apposition of the tendon stump as effectively as the Bunnell " buried core" technique using G 40 stainless steel wire.

4. The multiple barbed suture is an experimental suture for certain compact tendons capable of giving a neat and relatively atraumatic junction. It requires further study and development. It does not appear to make tendon repair technically easier, nor does it alter the indications for operation or management.

I am grateful to Professor Sir Herbert Seddon and Mr Donal Brooks for constant encouragement and help with the development and testing of the suture. The work reported here has been financed by The Laming Evans Orthopaedic Research Fund of the Royal College of Surgeons of England, and was performed at the Buckston Browne Research Farm under the generous direction of Professor D. Slome.

Considerable technical assistance has been generously given by Ethicon Ltd., Imperial Chemical Industries Lid., Dalau Specialized Plastics Ltd. and the National Research Development Corporation, and also by Mr E. Andrews of the Royal National Orthopaedic Hospital and Mr F. Watson of the Buckston Browne Research Farm. I am grateful also for the cooperation of Dr R. D. Teare. Dr H. A. Sissons and Dr P. Byers for fresh specimens of tendon. 


\section{REFERENCES}

Brooks, D. (1963): Personal communication.

Bunnell, S. (1954): Gig Pull-out Suture for Tendons. Journal of Bone and Joint Surgery, 36-A, 850.

Bunnell, S. (1956): Surgery of the Hand. Third edition. London: Pitman Medical Publishing Co. Ltd.

Jennings, E. R., Mansberger, A. R., Smith, E. P., and Yeager, G. H. (1952): A New Technique in Primary Tendon Repair. Surgery, Gynecology and Obstetrics, 95, 597.

McKee, G. K. (1945): Metal Anastomosis Tubes in Tendon Suture. Lancet, i, 659.

Mansberger, A. R., Jennings, E. R., Smith, E. P., and Yeager, G. H. (1951): A New Type Pull-out Wire for Tendon Surgery: A Preliminary Report. Bulletin of the School of Medicine, University of Maryland, 36, 119.

Mason, M. L. (1940): Primary and Secondary Tendon Suture: A Discussion of the Significance of Technique in Tendon Surgery. Surgery, Gynecology and Obstetrics, 70, 392.

Mollier, G. (1937): Beziehungen zwischen Form und Funktion der Sehnen im Muskel-Sehnen-KnochenSystem. Morphologisches Jahrbuch, 79, 161.

Potenza, A. D. (1962): Tendon Healing Within the Flexor Digital Sheath of the Dog: An Experimental Study. Journal of Bone and Joint Surgery, 44-A, 49.

Pulvertaft, R. G. (1965): Suture Materials and Tendon Junctures. American Journal of Surgery, 109, 346.

Verdan, C. E. (1960): Primary Repair of Flexor Tendons. Journal of Bone and Joint Surgery, 42-A, 647. 